\title{
A utilização dos vídeos educacionais do YouTube na Licenciatura em Matemática: presencial e a distância
}

\author{
Carla Denize Ott Felcher, UFRGS/UFPel, carlafelcher@gmail.com \\ Crisna Daniela Krause Bierhalz, Unipampa/Campus Dom Pedrito - \\ crisnakrause@gmail.com \\ Vanderlei Folmer, Unipampa/Campus Uruguaiana, vandfolmer@gmail.com
}

\section{Resumo}

Esta pesquisa problematiza o uso de vídeos educacionais do YouTube na formação do professor de Matemática. Utilizou-se como instrumento de pesquisa um questionário misto (perguntas abertas e fechadas), tendo como sujeitos 67 acadêmicos da Licenciatura em Matemática das duas modalidades: 45 presencial e 22 a distância. Os dados foram analisados e apresentados em gráficos, tabelas e nuvens de palavras, indicando os altos índices de utilização de vídeos do YouTube, sendo $100 \%$ no curso a distância. Público também responsável pela maior quantidade de vídeos assistidos no semestre. Em relação à disciplina que origina a maior busca por vídeos está o cálculo seguido da Matemática. Considerando a popularização do YouTube, reflete-se sobre a necessária discussão pedagógica, no processo de formação do professor de Matemática.

Palavras-chave: YouTube; Vídeos educacionais; Formação inicial; Professor de Matemática.

\section{The use of YouTube educational videos in the Degree in Mathematics: face-to-face and distance learning}

\begin{abstract}
This research questions the use of YouTube educational videos in the formation of the Mathematics teacher. A mixed questionnaire (open and closed questions) was used as a research instrument, having as subjects 67 undergraduate students in Mathematics of the two modalities: 45 face-to-face and 22 distance. The data were analyzed and presented in graphs, tables and word clouds, indicating the high rates of use of YouTube videos, being $100 \%$ in the distance course. Audience also responsible for the largest number of videos watched in the semester. In relation to the discipline that causes the greatest search for videos is the calculation followed by Mathematics. Considering the popularization of YouTube reflected on the necessary pedagogical discussion, in the process of training the teacher of Mathematics.
\end{abstract}

KEYWORDS:YouTube; Educational videos; Initial formation; Maths teacher.

\section{Introdução}

A Matemática é uma ciência que desperta inúmeros desafios, perspectivas e discussões. A começar pela metodologia empregada em sala de aula, que segundo Felcher, Pinto e Folmer (2018), não rara às vezes se resume a aplicar fórmulas e resolver listas de exercícios. Há também de se considerar os dados estatísticos na disciplina que 
não são animadores, entre eles o apresentado pelo Instituto Nacional de Estudos e Pesquisas Educacionais (INEP), em que o aproveitamento escolar no estado do Rio Grande do Sul para o ano de 2017, na disciplina de Matemática, considerando os nonos anos, é de 55,73\% insuficiente, 39,69\% básico e 4,59\% avançado (Brasil, 2018).

E quando a discussão se estende para as Licenciaturas em Matemática, a realidade não é diferente e também merece atenção. Segundo o MEC (2018), a falta de professores é mais crítica nas disciplinas de Física, Química e Matemática, sendo que nos últimos 15 anos se formaram 110 mil professores de Matemática, mas apenas 43 mil estão em sala de aula. Há ainda, os índices de evasão altíssimos na área, sendo que, apenas 65,5\% dos ingressantes concluem o curso.

Esses resultados suscitam algumas indagações: Por que a evasão nos cursos de Licenciatura em Matemática é tão acentuada? O que leva os estudantes a perceber que fizeram a escolha errada, originando a evasão da universidade ou do curso? Porque os estudantes não conseguem acompanhar regularmente, na maioria das situações, $o$ currículo do curso? De que forma as tecnologias são utilizadas oficialmente, inseridas no Projeto Pedagógico do Curso e extra oficial como investigado nesse estudo.

Tais questionamentos, além de retomarem discussões antigas no campo da formação de professores, relacionadas às matrizes dissociativas e fragmentadas das Licenciaturas, fundamentadas na racionalidade técnica, que considera a prática e a relação com a escola e a sala de aula elementos secundários, reforçam como aponta Arroyo (2007) a urgência das instituições formadoras incorporarem ao discurso e às práticas formativas do ensino superior uma nova epistemologia na formação de professores, mantendo uma relação mais próxima com as escolas e com as situações concretas do trabalho docente, as quais acenam para uma realidade que conecta estudantes e tecnologias digitais e suscita discussões no campo do ensino superior.

$\mathrm{Na}$ conjuntura das tecnologias digitais, destaca-se a utilização dos vídeos educacionais pelos licenciandos, considerando que o êxito no prosseguimento dos componentes curriculares e por que não dizer na conclusão da graduação está atrelado, em muitas vezes, a busca e a utilização destes. Vídeos online são usados cada vez mais no ensino superior como parte da explosão de ferramentas de Web 2.0 que estão disponíveis (Sherer; Shea, 2011).

Partindo da premissa de que a utilização de vídeos é uma realidade entre estudantes, o objetivo deste artigo é problematizar o uso de vídeos educacionais do YouTube na formação inicial do professor de Matemática. Foi aplicado um questionário misto a 67 acadêmicos de uma mesma Universidade Pública, situada no Rio Grande do Sul. Sendo, 45 sujeitos da Matemática presencial e 22 da Matemática a distância.

Os vídeos digitais, tanto no que se refere à produção, edição ou compartilhamento, caracterizam-se como movimentos da quarta fase das tecnologias digitais no Ensino da Matemática (Borba; Silva; Gadanidis, 2015), incentivados pelo advento da internet rápida, que possibilita estar conectado o tempo todo e em todo lugar. E assim, com um único aparelho é possível percorrer as fases de produção de um vídeo e compartilhar na rede.

O YouTube é um exemplo de um recurso de compartilhamento de vídeo, que tanto os professores, quanto os alunos podem usar de forma eficaz, dentro da sala de aula, como no seu exterior, para envolver os alunos e cumprir as metas de aprendizagem (Sherer; Shea, 2011). Há também, professores que compartilham seus próprios vídeos no YouTube, exemplificado por Borba, Silva e Gadanidis (2015), ao relatarem uma situação na qual uma aluna apresentou uma dúvida em um exercício de derivada, levando a professora a gravar um vídeo, postar o link no YouTube e compartilhar no grupo do Facebook. 
Porém, além de consumidores, os estudantes são também produtores de vídeos. Nesse sentido, Felcher, Pinto e Folmer (2018) relatam uma prática de produção de vídeos pelos estudantes sobre conteúdos matemáticos. A proposta envolveu 54 alunos de sétimo e oitavo ano do ensino fundamental, os quais produziram 13 vídeos. Tais estudantes citaram que a maior aprendizagem com a produção de vídeos está relacionada ao conteúdo. Constatação que qualifica a proposta, já que o uso da tecnologia deve ter como objetivo a potencialização da aprendizagem, sem perder o caráter conceitual.

Apesar do exposto, repositórios de vídeos como o YouTube nem sempre são permitidos nas escolas, com a justificativa de que promovem a distração dos estudantes (Borba; Silva; Gadanidis, 2015). Porém, o vídeo pode ser um instrumento poderoso na mão do professor, havendo a necessidade das escolas e professores se empenharem no conhecimento do seu potencial, para que possam aprender a manusear as ferramentas digitais a seu favor (Caetano; Falkembach, 2007).

Importante mencionar que as competências gerais da BNCC enfatizam fortemente o uso das tecnologias digitais, de maneira ética, crítica, considerando desde a comunicação, até a utilização para a resolução de problemas. De acordo com a $5^{\text {a }}$ competência:

\footnotetext{
Compreender, utilizar e criar tecnologias digitais de informação e comunicação de forma crítica, significativa, reflexiva e ética nas diversas práticas sociais (incluindo as escolares) para se comunicar, acessar e disseminar informações, produzir conhecimentos, resolver problemas e exercer protagonismo e autoria na vida pessoal e coletiva (BNCC, 2017).
}

Cabe ressaltar que nenhuma tecnologia é a solução para os problemas da educação, que tanto gestores, professores como os alunos precisam discutir quando e de que forma farão a utilização dos vídeos, ultrapassando a resistência e a negação pelo desconhecimento, afinal, "[...] discutir como utilizá-los ou incorporá-los, nos parece ser um caminho muito mais promissor do que evitá-los" (Borba; Silva; Gadanidis, 2015).

Assim, a intenção é que políticas públicas promovam a efetiva incorporação de tecnologias na prática pedagógica de docentes de cursos de licenciatura (Richit; Maltempi, 2005), para que sejam incorporadas discussões neste sentido nos colegiados dos cursos, tendo em vista que as tecnologias fazem parte do cotidiano, modificam a maneira de pensar, interagir com os outros e incentivam a construção de práticas colaborativa (Maltempi, 2008). Porém, é necessário o comprometimento do professor com a sua formação e na tentativa de melhorar a qualidade do ensino.

\section{Percurso metodológico}

No intuito de alcançar o objetivo do artigo foi aplicado, um questionário misto com duas perguntas fechadas e quatro abertas, a 67 acadêmicos, sendo 45 do curso de Licenciatura em Matemática presencial e 22 da Matemática a distância, de uma Universidade pública do Rio Grande do Sul. Os acadêmicos participantes desta pesquisa foram escolhidos aleatoriamente, independente do semestre do curso e das disciplinas que estão cursando.

Os dados produzidos pelo questionário foram analisados e apresentados em forma de gráficos, tabelas e nuvens de palavras, geradas pelo software livre, WordArt. Segundo Borba, Almeida e Gracias (2018), as nuvens de palavra apresentam em destaque as palavras que aparecem com maior frequência no texto, sendo difícil diferenciar o qualitativo do quantitativo. Assim, segundo os autores, "podemos partir de uma 
ferramenta quantitativa e lançar um olhar qualitativo" (Borba; Silva; Gadanidis, 2018, p. 79).

\section{Apresentando e analisando os dados}

O YouTube é uma plataforma de compartilhamento de vídeos,que funciona como uma das subsidiárias da Google. Tem como missão dar a todos uma voz e revelar o mundo (YouTube, 2018), não foi feita para fins educacionais, mas acaba se tornando aliada de projetos que não demonizavam novas formas de comunicação (Borba; Silva; Gadanidis, 2015).

Diante disso, no contexto educacional, segundo Schneider, Caetano e Ribeiro (2012), a proliferação de vídeos no YouTube cresce exponencialmente, em maio de 2012, uma busca por vídeos com a palavra Matemática no título resultou 71300 vídeos, já a busca com a palavra cálculo no título apresentou 16600 vídeos.

Considerando o exposto que enaltece a importância e as múltiplas possibilidades dos vídeos educacionais, incluída a experiência que mostra que não são raras as vezes em que os alunos utilizam tais ferramentas, principalmente do YouTube, buscou-se nesta investigação problematizar o uso de vídeos educacionais dessa plataforma.

Os acadêmicos, primeiramente, foram indagados se assistiam vídeos do YouTube, com o objetivo de aprender conteúdos acadêmicos. Os acadêmicos da Licenciatura em Matemática presencial, 95,5\% responderam que sim, enquanto da Matemática a distância, 100\% responderam sim, que assistem vídeos educacionais do YouTube.

Nessa lógica, acadêmicos da Licenciatura em Matemática, participantes da pesquisa, em sua totalidade, assinalaram que o YouTube é importante à educação (Bottentuit Júnior; Coutinho, 2009). Complementando, Jones e Cuthrell (2011) citam que o vídeo tem potencial promissor à educação, especialmente à luz do século XXI, destacando resultados positivos em relação ao aproveitamento dos alunos, por meio da tecnologia do vídeo

A preferência por vídeos, segundo Borba e Oechsler (2018), está relacionada às possibilidades de pausar, retroceder e adiantar a explicação no momento oportuno, além da busca por explicações com uma linguagem classificada como mais fácil que a do professor, responsável pela disciplina.

Os acadêmicos que responderam sim na questão 1, deveriam prosseguir respondendo o questionário. A segunda pergunta versou sobre o número de vídeos assistidos por semestre (média), tendo a possibilidade de assinalar uma das quatro alternativas apresentadas na sequência do gráfico.

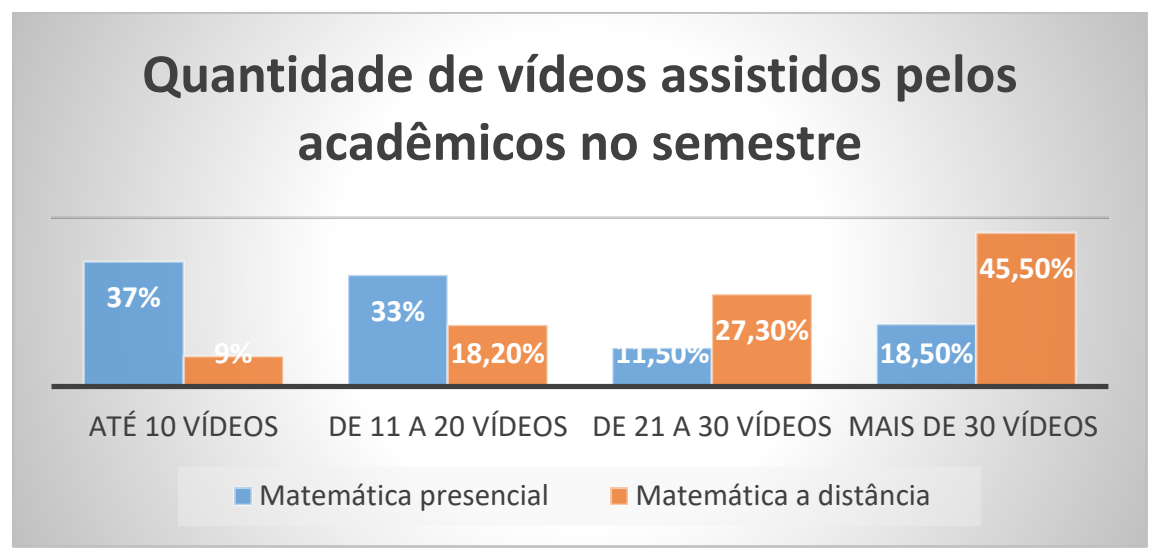

Figura 1: Quantidade de vídeos assistidos pelos acadêmicos no semestre 
Fonte: dados da pesquisa

A figura 1, mostra uma divisão entre os acadêmicos da Matemática presencial e a distância, no que tange ao número de vídeos que assistem, sendo que no curso presencial o quantitativo de discentes que assiste menos de 20 vídeos no semestre é maior e no curso a distância o quantitativo é maior para os que assistem mais de 21 vídeospor semestre. Segundo pesquisa realizada por Pearson (2018), acadêmicos apontaram que YouTube, aplicativos e vídeos são formas preferidas de aprendizado da Geração Z. Enquanto a Geração Millennials prefere livros impressos para o aprendizado.

Analisando a figura surge uma curiosidade relacionada aos cursos a distância, pois estes possuem como base do seu material pedagógico apostilas, artigos em pdf, ebooks, vídeo aulas, dessa forma, a hipótese inicial era de que a busca por vídeos do YouTube deste público seria menor, fato que não se comprovou. Para Moore (2007), a proliferação de vídeos amadores pode estar comprometendo a qualidade do material produzido para o ensino a distância. No entanto, para Mattar (2009), hoje, existe um crescente repositório de mídias para ser utilizado em $\mathrm{EaD}$, que combinados com inúmeras ferramentas também disponíveis online, trazem novas oportunidades para integrar conteúdo multimídia. Assim, o YouTube, emergiu na web e precisa ser incorporada às estratégias pedagógicas, inclusive de design instrucional.

O próximo questionamento foi sobre o objetivo pelo qual os acadêmicos assistem vídeos do YouTube. Através da figura 2, é possível aferir que o propósito dos acadêmicos está relacionado ao esclarecimento de dúvidas, na sequência, aprender, revisar conceitos e, por fim, buscar truques.

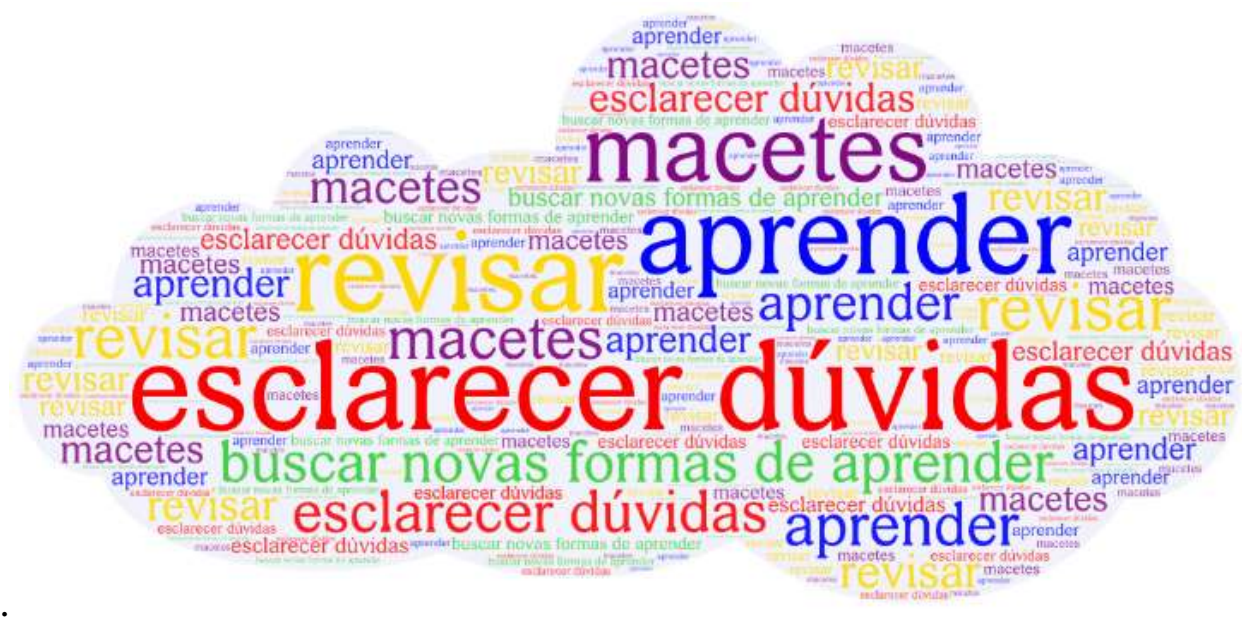

Figura 2: Nuvem de palavra que apresenta os objetivos com os quais os acadêmicos assistem vídeos do YouTube

Fonte: dados da pesquisa

Segundo Schneider, Caetano e Ribeiro (2012), um dos fenômenos de audiência do YouTube veio justamente de um público de jovens e crianças, que, por iniciativa própria, acessavam os vídeos para esclarecer suas dúvidas de aprendizado. Complementando, Domingues (2014) cita que os jovens utilizam vídeos da internet também como fonte de pesquisa, para fins de estudo, assim, é comum os alunos mencionarem a busca por vídeos no YouTube para compreender conceitos ou muitas vezes para conseguir realizar exercícios. 
Porém, mesmo com tamanho, volume e diversidade de informações disponíveis hoje, é importante salientar o expresso por Ferrés (1996, p. 33), quando revela que "o vídeo não substitui o professor, porém impõe mudanças em sua função pedagógica”. A necessidade de mudança na prática pedagógica é no sentido do professor ser um mediador, um orientador dos processos de ensino e aprendizagem, pois, apenas transmitir informações, por exemplo, os vídeos podem fazer com eficácia, ao professor cabe contextualizar com exemplos da sua prática, relacionar os conteúdos com o cotidiano e com as questões regionais locais, ultrapassando a simples memorização e levando a construção de uma aprendizagem significativa.

A aquisição da informação, dos dados, dependerá cada vez menos do professor. "As tecnologias podem trazer, hoje, dados, imagens, resumos de forma rápida e atraente. O papel do professor - o papel principal - é ajudar o aluno a interpretar esses dados, a relacioná-los, a contextualizá-los" (Moran; Masseto; Behrens, 2008, p. 29-30).

O próximo questionamento versou sobre a relação entre as disciplinas e os vídeos do YouTube acessados pelos acadêmicos. Nas duas modalidades, a disciplina de Cálculo faz com que os licenciandos busquem os vídeos (quadro 1). Esse dado permite a elaboração de algumas hipóteses: seria o Cálculo a disciplina na qual os alunos encontram maiores dificuldades ao longo do curso? O alto nível de abstração da disciplina tem relação direta com a dificuldade do aluno? Existe relação entre a dificuldade e as metodologias utilizadas pelo professor? Indícios como a falta de base, provenientes da baixa qualidade do ensino fundamental e ensino médio caracterizam-se como resultado significativo neste contexto? Somam-se a estas indagações os altos índices de evasão e reprovação na disciplina de Cálculo, objeto de estudos nacionais e internacionais, que investigam as causas das dificuldades apresentadas e buscam alternativas para amenizar a situação (Nasser; Souza; Torraca, 2012).

Quadro 1: Disciplinas sobre os quais os acadêmicos assistem vídeos do YouTube

\begin{tabular}{|c|c|}
\hline Matemática presencial & Matemática a distância \\
\hline Cálculo 26 & Cálculo 13 \\
Matemática 15 & Matemática 7 \\
Geometria 10 & Aritmética 4 \\
Física 9 & Física 3 \\
Álgebra 7 & Geometria 3 \\
Aritmética 4 & Trigonometria 2 \\
Instrumentação para o ensino 2 & Todas 2 \\
Equações Diferenciais Ordinárias 2 & Álgebra 1 \\
Educação Matemática 2 & Língua Portuguesa 1 \\
Lema 1 & \\
Lógica 1 & \\
Trigonometria 1 & \\
Programação 1 & \\
Análise real 1 &
\end{tabular}

Fonte: dados da pesquisa

Para Borba e Oescher (2018), no YouTube, encontram-se vídeos diversos, desde jogos até conteúdos didáticos das mais variadas disciplinas. O que proporciona a utilização para sanar dúvidas, complementar ou aprofundar conceitos das disciplinas escolares. Acreditamos que todos devam ser capazes de encontrar comunidades de 
suporte, eliminar obstáculos, ultrapassar as fronteiras e reunir-se em torno de interesses e paixões compartilhadas. (YouTube, 2019).

Na sequência, os acadêmicos deveriam responder se o YouTube é importante na formação, justificando a resposta. $\mathrm{O}$ quadro 2, mostra que para os acadêmicos da Matemática EaD a importância do YouTube é ainda maior, pois, 59\% deles destaca a plataforma como muito importante. Já entre os acadêmicos da Matemática presencial o destaque é para a classificação importante com 46,5\%. O número total de aluno que considera de pouca importância os vídeos perfaz 11,5\%, ou seja, resultado que equivale a 8 dos 67 acadêmicos.

Quadro 2: A importância do YouTube para os acadêmicos

\begin{tabular}{|c|c|c|c|c|c|}
\hline \multicolumn{3}{|c|}{ Matemática presencial } & \multicolumn{3}{c|}{ Matemática a distância } \\
\hline Importante & $\begin{array}{c}\text { Muito } \\
\text { importante }\end{array}$ & $\begin{array}{c}\text { Pouco } \\
\text { importante }\end{array}$ & Importante & $\begin{array}{c}\text { Muito } \\
\text { importante }\end{array}$ & $\begin{array}{c}\text { Pouco } \\
\text { importante }\end{array}$ \\
\hline $46,5 \%$ & $42 \%$ & $11,5 \%$ & $41 \%$ & $59 \%$ & $0 \%$ \\
\hline
\end{tabular}

Fonte: dados da pesquisa

Entre as justificativas para os índices acima, destaca-se:

\begin{abstract}
"Para nós alunos da Matemática a distância é de extrema importância, pois, é o método mais rápido para recorrermos, já que no fórum de dúvidas a resposta demora" (Acadêmico da Matemática a distância)

"O YouTube é importante. Sem ele creio que não conseguiria concluir o curso. No YouTube encontramos vídeos para todas as nossas dúvidas e podemos acessar a qualquer hora. A dúvida é satisfeita rapidamente e podemos prosseguir nos estudos"(Acadêmico da Matemática presencial)
\end{abstract}

Os dados apresentados no quadro 2 e as justificativas dos acadêmicos mostram que o YouTube é importante, divergindo do exposto por Mattar (2009). Também Juhasz (2008) trata de maneira pessimista o YouTube, entre os motivos destaca: o amadorismo dos vídeos do YouTube que torna difícil seu aproveitamento acadêmico; o ensino superior está ligado ao complexo, não a simples diversão proporcionada pelo YouTube; o caos de informação e poder que caracterizam o YouTube não combina com o controle e a estrutura necessários para a educação.

Há supostamente no mundo acadêmico uma necessidade de reafirmar uma complexidade que distancia prazer do ensino e aprendizagem. Nas palavras de Mattar (2009), seria uma resistência e uma recusa da academia em mudar. Porém, Para Tan (2013), o YouTube é um ambiente de aprendizagem informal, formado com base no conteúdo do usuário e com riqueza de material disponível, podendo cada um escolher o percurso de navegaçãoe assim construir seu ambiente de aprendizagem.

Os acadêmicos foram questionados a respeito dos fatores considerados no momento da escolha dos vídeos do YouTube e, as respostas foram organizadas em 3 categorias, que estão relacionadas ao vídeo, ao canal e ao autor do vídeo, conforme figura 3. 


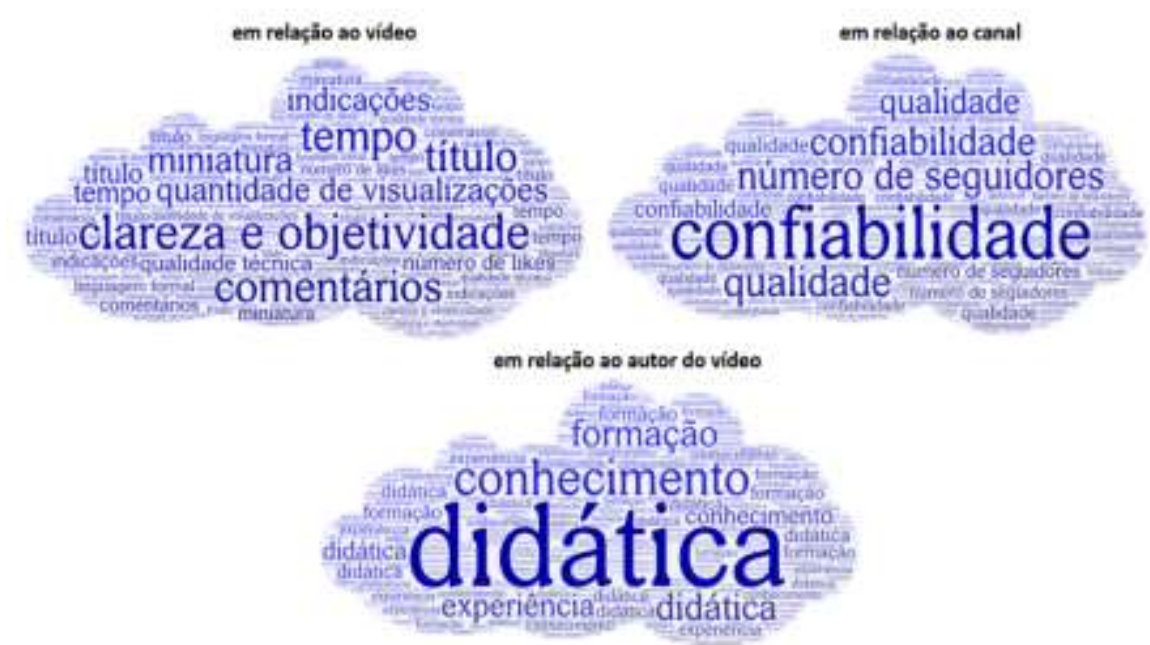

Figura 3: Motivos que justificam a escolha de vídeos

Fonte: dados da pesquisa

Em relação à categoria vídeos, os acadêmicos apontam clareza e objetividade como o principal motivo considerado. Nesse sentido, Schneider, Caetano e Ribeiro (2012) ressaltam que para a construção de um vídeo educacional, o usuário procura por uma informação clara e objetiva. Assim, Bergmann e Sams (2018) citam que se está ensinando equações do segundo grau, ensine apenas equação do $2^{\circ}$ grau.

Os acadêmicos também citaram a confiabilidade no canal, estabelecida em razão dos Youtubers possuírem seguidores, destacando-se aqui a afinidade com o tema postado, o que os leva a curtir, seguir e compartilhar essas publicações.Assim, se estabelece um vínculo entre o Youtubers e os seguidores do canal.

Sobre a autoria do vídeo, a didática é o motivo mais citado pelos acadêmicos. Nesse sentido,Schneider, Caetano e Ribeiro (2012) alertam para a necessidade de relação entre som, imagem e texto de maneira interconectada e relacionada através dos títulos, legendas e texto. Reforça-se que o vídeo precisa transmitir a mensagem, utilizando os recursos apropriados e adequados à necessidade.

Mattar (2009) afirma que o vídeo tem um poder de ilustração muito forte, prende atenção quando bem estruturado e elaborado. Tem movimento, áudio e, muitas vezes, é autoexplicativo. Nessa perspectiva, o YouTube, segundo Tan (2013), pode desempenhar um papel importante na formação de comunidades online, ampliando suas interações (discente-discente) em um ambiente informal fora da sala de aula, facilitando interações que não seriam previamente realizadas. E apoiando o desenvolvimento de laços sociais que se estendem do ambiente formal da sala de aula para a informalidade do cyberespaço.

Por fim, mesmo diante da exaltação do potencial e da importância do YouTube na formação inicial do professor, problemas e limites também atingem tal plaraforma. Direcionando-se para questões da academia, Mattar (2009) salienta preocupação com a qualidade e o valor acadêmico dos vídeos, principalmente face ao conteúdo gerado pelos próprios usuários. Mais um motivo que justifica a necessidade de discussão do consumo de vídeos na formação do professor, tanto na perspectiva do próprio acadêmico construir um olhar crítico sobre o material, quanto para a sua futura prática.

\section{Considerações e perspectivas futuras}

As tecnologias digitais estão presentes no dia a dia dos indivíduos, em menor ou maior grau. Assim, produzir vídeos e compartilhar, ou assistir e compartilhar vídeos do YouTube é uma prática comum no século XXI. Receitas, viagens, dicas, saúde, beleza, 
entretenimento, e por que não, conceitos acadêmicos dos mais diversos níveis compõem o conteúdo do YouTube.

A partir da popularização dos vídeos do YouTube, esta investigação aponta para um enorme número de acadêmicos que utiliza esses vídeos na formação de professor de Matemática, tanto na modalidade presencial como a distância, sendo que entre os acadêmicos da Matemática a distância essa porcentagem é de 100\%. Esse mesmo público também assiste no semestre o maior número de vídeos da plataforma. Assim, os acadêmicos consideram de grande importância o YouTube na formação, justificando que o maior motivo da busca é para esclarecer dúvidas na disciplina de Cálculo.

A importância dada ao YouTube e, portanto, da ferramenta vídeos, pelos acadêmicos deve suscitar discussões entre os professores. É preciso (re)pensar o uso dos vídeos no processo de ensino e aprendizagem, não como resolução aos problemas da educação, mas como mais uma ferramenta disponível e que poderá contribuir no processo, hoje de formação do acadêmico e amanhã na formação dos seus alunos. Afinal, entende-se que o professor que experimentar tais práticas e discussões na formação, mais probabilidade terá de implementá-las em sua docência.

Considerando as possibilidades vislumbradas quando a discussão é sobre vídeos e que os acadêmicos do Ensino Superior tem tamanha intimidade com YouTube, como perspectivas futuras, têm-se como propósito verificar se na Educação Básica essa plataforma também é utilizada, em qual(is) disciplina(s) e com que frequência.

\section{Referências bibliográficas}

ARROYO, M. G. Condição docente, trabalho e formação. In: SOUZA, J. V. A. (Org.). Formação de professores para a educação básica: dez anos da LDB. Belo Horizonte: Autêntica, 2007.

BERGMANN, J.; SAMS, A. Sala de aula invertida: uma metodologia ativa de aprendizagem. Rio de Janeiro: LTC, 2018.

BORBA, M. C.; SILVA, R. S. S; GADANIDIS, G. Fases das tecnologias digitais em Educação Matemática. Belo Horizonte: Autêntica, 2015.

BORBA, M. C; ALMEIDA, H. R. F. L; GRACIAS, T. A. S. Pesquisa em ensino e sala de aula: Diferentes vozes em uma investigação. Belo Horizonte: Autêntica, 2018.

BORBA, M. C. OESCHER, V. Tecnologias na educação: o uso dos vídeos na sala de aula. Revista Brasileira de Ensino de Ciência e Tecnologia, v. 11, n. 2, 2018.

BOTTENTUIT JUNIOR, J. B.; COUTINHO, C. P. Desenvolvimento de vídeos educativos com o Windows Movie Maker e o YouTube: uma experiência no Ensino Superior. 2009. Disponível em: http://hdl.handle.net/1822/9019. Acesso em: 20 jan. 2019.

BRASIL. Base Nacional Comum Curricular. BNCC. 2017. Disponível em: http://basenacionalcomum.mec.gov.br/abase/. Acesso em: 15 fev. 2019.

CAETANO, S. V. N.; FALKEMBACH, G. A. M. YOU TUBE: uma opção para uso do vídeo na EAD. Renote, v. 5, n. 1, 2007. 
DOMINGUES, N. S. O papel do vídeo nas aulas multimodais de Matemática Aplicada: uma análise do ponto de vista dos alunos. 2014. Dissertação (Mestrado em Educação Matemática) - Universidade Estadual Paulista "Júlio de Mesquita Filho", Rio Claro, 2014.

FELCHER, C. D. O.; PINTO, A. C. M.; FOLMER, V. Performance Matemática Digital: o aluno produzindo vídeos e construindo conceitos. Revista Brasileira De Ensino De Ciências E Matemática, v. 1, n. 1, 2018.

FERRÉS, J. Vídeo e educação. Porto Alegre: Artes Médicas, 1996.

JONES, T.; KRISTEN, C.YouTube: Educational Potentials and Pitfalls, Computers in the Schools,2011. 28:1,75-85.

MALTEMPI, M. V. Educação matemática e tecnologias digitais: reflexões sobre prática e formação docente/Mathematics education and digital technologies: Reflexions about the practice in teacher education. Acta Scientiae, v. 10, n. 1, p. 59-67, 2008.

MATTAR, J. YouTube na educação: o uso de vídeos em EaD. São Paulo: Universidade Anhembi Morumbi, 2009.

MOORE, M.; KEARSLEY, G. A educação a distância: uma visão integrada. Trad. Roberto Galman. São Paulo: Thomson Learning, 2007.

NASSER, L.; SOUSA, G.; TORRACA, M. Transição do ensino médio para o superior: como minimizar as dificuldades em cálculo. V Seminário Internacional de Pesquisa em Educação Matemática (em CD). Petrópolis, RJ, 2012.

PEARSON. New Research Finds YouTube, Video Drives Generation $\mathbf{Z}$ Learning Preference. Disponível em: https://www.pearson.com/corporate/news/media/newsannouncements/2018/08/new-research-finds-youtube--video-drives-generation-Zlearning-p.html?fbclid=IwAR3 YjlDUDgi1YT8vDhL2SDSWovVnsfh67FuIVvbb9Gje0X1ptDpMO2Er0. Acesso em: 06 fev. 2019.

RICHIT, A.; MALTEMPI, M. V. A formação profissional docente e as mídias informáticas: reflexões e perspectivas. BOLETIM GEPEM-Grupo de Estudos e Pesquisas em Educação Matemática, n. 47, p. 91-102, 2005.

SCHNEIDER, C. K.; CAETANO, L.; RIBEIRO, L. O. M. Análise de vídeos educacionais no youtube: caracteres e legibilidade. Renote, v. 10, n. 1, 2012.

SHERER, P.; SHEAT.Using Online Video to Support Student Learning and Engagement, College Teaching, 2011, 59:2, 56-59.

TAN, E. Informal learning on YouTube: exploring digital literacy in independent online learning, Learning, Media and Technology, 2013, 38:4, 463-477.

$\begin{array}{lllll}\text { YOUTUBE. Sobre } & \text { o } & \text { Youtube. } & \text { Disponível }\end{array}$ em:<http://www.youtube.com/t/about_youtube>. Acesso em: 05 fev 2019. 